\title{
MESIN DESTILASI PENGOLAHAN SAMPAH PLASTIK MENJADI BAHAN BAKAR MINYAK MENGGUNAKAN KONDENSOR BERTINGKAT DAN PENDINGIN KOMPRESI UAP
}

\author{
Arwizet $^{1^{*}}$ \\ ${ }^{1}$ Jurusan Teknik Mesin, Fakultas Teknik, Universitas Negeri Padang \\ *arwizet1969@gmail.com
}

\begin{abstract}
Abstrak - Studi ini mencoba mencari solusi dari penggunaan bahan bakar fosil (fossil energy) untuk menggunakan sampah plastik menjadi bahan bakar minyak bersih dan layak hidup. Penelitian ini bertujuan untuk membangun dan meneliti mesin distilasi dengan dua sistem siklus pengolahan sampah plastik menjadi bahan bakar minyak.. Pengujian dilakukan dengan dua cara: tes pertama tanpa tes plastik), uji kedua dengan pembakaran sampah plastik. Hasil pengujian pada kondisi mesin kosong untuk pengaturan thermostate 4 , terlihat pencapaian suhu rata-rata terendah di ruang pendingin yang bisa diraih dengan mendinginkan rentang mesin $5{ }^{\circ} \mathrm{C}$ sampai $6^{\circ} \mathrm{C}$. Pada setting termostat 6 , prestasi temperatur di ruang pengeringan rata-rata terendah berkisar antara $2^{\circ} \mathrm{C}$ sampai $3^{\circ} \mathrm{C}$. Sedangkan untuk pengujian kelembaban udara yang mengandung limbah plastik di ruang pengeringan sedikit lebih tinggi bila dibandingkan dengan pengujian kosong yang sekitar $67 \%$ sampai 72\%. Koefisien Performansi (COP) untuk pengujian maksimal kosong atau mengandung pengujian santan untuk pengaturan termostat 4 dan 6 berkisar antara 0,67 sampai 0,69.
\end{abstract}

Kata kunci: Limbah plastik, Terephtalate Polyethylene (PET), High Density Polyethylene (HDPE), mesin distilasi, koefisien kinerja (COP)

Abstract- This study tried to find solutions from the use of fossil fuels (fossil energy) to use plastic waste into clean fuel oil and worthy life. This research is aimed to building and researching a distillation machine with two cycles system processing plastic waste into fuel oil. Testing is done in two ways: first test without the plastic burning), the second test with the burning of plastic waste. The test results on the conditions the engine empty for setting thermostate 4, looks achievements lowest average temperature in the cooling chamber that can be achieved by cooling the engine range $5^{\circ} \mathrm{C}$ to $6^{\circ} \mathrm{C}$. At thermostate setting 6 , achievements of temperartur in the drying chamber the lowest average ranged from $2^{\circ} \mathrm{C}$ to $3^{\circ} \mathrm{C}$. As for the testing of air moisture containing plastic waste in the drying chamber is slightly higher when compared to the empty testing which is about $67 \%$ to $72 \%$. Coefficient Of perfomance (COP) for testing the maximum empty or contains coconut milk testing for thermostate setting 4 and 6 ranged from 0.67 to 0.69 .

Key words: Plastic waste, Terephtalate of Polyethylene (PET) and High Density Polyethylene (HDPE), distillation machine, coefficient of performance (COP)

\section{Pendahuluan}

Dampak krisis energi dunia khususnya Minyak Bumi sejak tahun 1973 masih terasa hingga saat ini. Krisis minyak bumi tersebut terasa sangat mempengaruhi perekonomian dunia, termasuk Indonesia. Sebetulnya sejak tahun 2004 Indonesia telah menjadi negara net importir minyak, artinya Indonesia sudah tidak mampu lagi memenuhi kebutuhan energi dalam negeri terhadap minyak bumi.
Saat ini harga minyak dunia telah menembus harga di atas US \$100/barel. Kenaikan harga minyak dunia tentu saja akan merugikan Indonesia, karena hal tersebut akan membuat biaya anggaran subsidi minyak bumi semakin membengkak. Lonjakan harga minyak hingga di atas US $\$ 100 /$ barel tentu juga akan mempengaruhi aktifitas perekonomian di berbagai belahan dunia. Beberapa waktu lalu kelangkaan BBM merupakan pemandangan 
yang bisa dijumpai di berbagai daerah di tanah air. Dari segi APBN, subsidi BBM yang mencapai $25 \%$ dinilai sebagai sesuatu yang tidak wajar dan memberatkan. Krisis bahan bakar minyak (BBM) ini disinyalir merupakan penyebab melemahnya rupiah terhadap dolar.

Ketergantungan terhadap bahan bakar fosil memiliki ancaman serius, yakni: (1) menipisnya cadangan minyak bumi yang diketahui (bila tanpa temuan sumur minyak baru), (2) kenaikan/ketidakstabilan harga akibat laju permintaan yang lebih besar dari produksi minyak. Pemerintah sebenarnya telah menyiapkan berbagai peraturan untuk mengurangi ketergantungan terhadap bahan bakar fosil (misalnya: Kebijakan Umum Bidang Energi (KUBE) tahun 1980 dan Keputusan Menteri Pertambangan dan Energi No 996.K/43/MPE/1999 tentang prioritasi penggunaan bahan bakar terbarukan untuk produksi listrik yang hendak dibeli PLN). Namun sayang sekali, pada tataran implementasi belum terlihat adanya usaha serius dan sistematik untuk menerapkan energi terbarukan guna substitusi bahan bakar fosil.

Konsumsi minyak bumi dengan berbagai turunannya (bensin, solar dan minyak tanah) semakin memberatkan anggaran belanja Negara (APBN). Sehingga menimbulkan berbagai usulan agar harga minyak di Indonesia dinaikkan. Bensin yang dulu berharga $\mathrm{Rp} 4.500 /$ liter saat ini telah menjadi Rp 6.500/liter. Pembatasan subsidi minyak oleh negara jelas akan berdampak pula terhadap perekonomian masyarakat. Diperkirakan harga semua komoditi akan naik teruatama kebutuhan bahan pokok, hal ini jelas akan sangat memberatkan ekonomi masyarakat. Menteri BUMN Dahlan Iskan mengatakan (dalam Padang Ekspress, 20 Maret 2012) jika tidak ingin terbebani oleh bahan bakar minyak (BBM) marilah kita ramai-ramai meninggalkan bahan bakar minyak. Himbauan ini sepertinya sebuah solusi, tetapi meninggalkan bahan bakar minyak dalam waktu singkat sangat sulit dilakukan karena hampir semua sektor kehidupan tidak terlepas dari penggunaan bahan bakar minyak. Misalnya untuk transportasi, pembangkit listrik, keperluan rumah tangga dan sebagainya semuanya memerlukan bahan bakar minyak. Untuk mengatasi kebutuhan bahan bakar minyak diperlukan solusi lain seperti konversi dari minyak ke gas, atau dari penggunaan minyak ke tenaga listrik. Beberapa pengembangan teknologi dewasa ini di Indonesia diarahkan untuk alih penggunaan bahan bakar minyak ke berbagai bentuk lain seperti pembuatan mobil listrik, motor litrik, motor berbahan gas (LPG) dan sebagainya. Penelitian ini mencoba mencari solusi dari penggunaan bahan bakar minyak (energi fossil) ke pemanfaatan sampah plastik dan bahan lainnya menjadi bahan bakar minyak yang bersih dan layak pakai.

Sampah adalah suatu bahan yang dibuang dari sumber hasil aktivitas manusia maupun alam yang belum memiliki nilai ekonomis. Secara garis besar, sampah dibedakan menjadi tiga jenis yaitu: 1) sampah anorganik/kering contoh: logam, besi, kaleng, plastik, karet, botol, dll yang tidak dapat mengalami pembusukan secara alamai; 2) sampah organik/basah contoh: sampah dapur, sampah restoran, sisa sayuran, rempahrempah atau sisa buah dan lain-lain yang dapat mengalami pembusukan secara alami; 3) sampah berbahaya contoh: baterai, botol racun nyamuk, jarum suntik bekas dan lainlain.

Sampah plastik dalam jumlah banyak merupakan suatu faktor yang dapat menyebabkan polusi pada lingkungan (tanah dan air), jika tidak dikelola dengan baik. Dalam banyak hal sampah plastik baru digunakan untuk pembuatan bahan kerajinan tangan seperti pembuatan bunga, hiasan dinding, tas jinjing, dompet dan sebagainnya. Maka pada penelitian ini akan di kembangkan Mesin destilasi sistem dua siklus pengolah sampah plastik menjadi bahan bakar minyak (BBM) yang bersih dan layak pakai.

Diharapkan dengan adanya mesin ini, dapat menjadi sebuah terobosan baru dalam mengatasi kebutuhan akan bahan bakar minyak dan sekaligus untuk mengatasi masalah sampah plastik sebagai sumber 
polusi pada lingkungan. Pada akhirnya penelitian ini diharapkan akan dapat menjadi solusi atas dua permasalahan yaitu masalah kebutuhan akan bahan bakar minyak dan permasalahan polusi oleh sampah plastik terhadap lingkungan sekitar. Ini juga merupakan sebuah terobosan inovasi teknologi tepat guna dalam proses pengolahan sampah menjadi bahan bakar minyak.

\section{StUdi PUSTaka}

\section{A.Definisi Destilasi Secara Umum}

Destilasi pada dasarnya adalah proses pemisahan suatu campuran menjadi dua atau lebih produk, lewat eksploitasi perbedaan kemampuan menguap komponen-komponen dalam campuran. Dalam kata lain destilasi adalah suatu cara pemisahan larutan dengan menggunakan panas sebagai pemisah (separating agent). Proses ini dilakukan di dalam suatu kolom baki (tray column) atau kolom dengan isian (packing column), sehingga dapat terjadi kerja pemisahan yang lebih baik.

Umumnya metode destilasi digunakan untuk memisahkan komponen-komponen dari suatu larutan. Ada beberapa metode destilasi yang sering digunakan dalam industri yakni:

1) Destilasi kilat (flash destillation) \& kondensasi parsial

2) Destilasi sederhana (simple destilla-tion)

3) Destilasi uap (steam destillation)

4) Distilasi kilat (flash) \& kondensasi parsial

Distilasi kilat (flash) terdiri dari penguapan sebagian tertentu zat cair, sehingga uap yang keluar berada dalam kesetimbangan dengan zat cair yang tersisa. Uap ini lalu dipisahkan dari zat cair dan dikendensasikan. Peralatan yang digunakan pada destilasi jenis ini terdiri dari: heat exchanger (atau kadangkadang ketel pipa untuk komponenkomponen dengan titik didih tinggi) dan satu tangki pemisah (flash drum). Pada proses flashing, suatu umpan yang volatil dialirkan melalui pemanas, kemudian dilewati ke keran penurun tekanan (choke valve), lalu masuk ke tangki pemisah. Fase uap dan fase cair yang meninggalkan tangki pemisah dianggap berada dalam kesetimbangan.

Satuan yang digunakan biasanya dalam mol atau mol/jam. Fraksi mol untuk menyatakan konsentrasi. D adalah uap yang terbentuk (pada flashing) atau tersisa pada kondensasi parsial. W adalah cairan yang diambil atau produk bawah (residu). Rasio $\mathrm{D} / \mathrm{F}$ adalah fraksi dari umpan yang teruapkan pada proses pemisahan flashing. Untuk basis satu mol umpan yang masuk, dapat disusun neraca massa untuk komponen i adalah:

$$
z_{i F}=(D / F) y_{i D}+(1-D / F) x_{i W}
$$

Pada sistem dua komponen (biner) neraca massa disusun untuk komponen yang paling volatil, dan subskrip i dapat dihilangkan.

\section{1) Perhitungan Destilasi Flash (Kilat)}

Persamaan (1) dapat dituliskan untuk komponen yang lebih mudah menguap (volatil) dalam campuran biner sebagai berikut :

$$
\begin{aligned}
& y_{D}=-(W / D) x_{W}+(F / D) z_{F} \\
& \text { atau, } \\
& y_{D}=-[(1-D / F) /(D / F)] x_{W}+z_{F} /(D / F)
\end{aligned}
$$

\section{(3)}

Di mana $y_{D}$ dan $x_{W}$ adalah komposisi pada kesetimbangan. Neraca massa total dan neraca komponen diperlukan untuk menghitung komposisi dari campuran dua fase yang terbentuk. Apabila $z_{i}$ melambangkan fraksi mol komponen i dalam arus umpan untuk campuran multi komponen. Neraca massa total :

$$
F=D+W
$$

Neraca komponen i adalah :

$$
\begin{array}{r}
z_{i} F=y_{i} D+x_{i} W \\
f_{i}=d_{i}+w_{i}
\end{array}
$$

Dengan memasukkan hubungan kesetimbangan $y_{i}=K_{i} x_{i}$ dan menyusun ulang persamaan (1), untuk memperoleh $x_{i}$ maka,

$$
x_{i}=z_{i}\left[(1+D / W)\left(1+K_{i} D / W\right)\right]
$$


Persamaan (6) memungkinkan kita menghitung komposisi cairan residu jika suhu flash, tekanan total, komposisi umpan, dan rasio D/W yang tertentu.

Komposisi fase uapnya adalah, $y_{i}=z_{i}\left[(1+D / W) /\left(1+W / K_{i} D\right)\right]$ (7)

Persamaan-persamaan tersebut dapat digunakan untuk menghitung komposisi tiap fase, dengan syarat;

$$
\sum y_{i}=1,0 \quad \text { dan }
$$

$$
\sum x_{i}=1,0
$$

Untuk penyelesaian dengan grafis persamaan dapat dituliskan :

$$
\begin{gathered}
y_{D}=-(W / D) x_{W}+(F / D) z_{F} \\
y_{D}=-[(1-D / F) /(D / F)] x_{W}+z_{F} /(D / F)
\end{gathered}
$$

atau

$$
y_{D}=-[(1-\psi) /(\psi)] x_{W}+z_{F}(1 / \psi),
$$

Dimana:

$$
\Psi=D / F
$$

\section{- Perhitungan Kondensasi Parsial}

Prinsip pemisahan secara kondensasi parsial sama dengan pemisahan flash. Operasi kondensasi parsial adalah kebalikan dari pemisahan flash. Metodanya adalah melewatkan campuran uap di atas suatu permukaan yang dingin, sehingga dapat menyebabkan terjadinya perubahan komposisi.

Pada kondensasi parsial, umpan yang berupa uap akan didinginkan dalam heat exchanger, biasa disebut sebagai kondenser, hingga mencapai suhu dew point-nya. Dengan pendinginan lebih lanjut akan terjadi pengembunan. Campuran uap-cair yang diperoleh setelah pendinginan dimasukkan ke dalam suatu tangki pemisah di mana cairan akan terkumpul dan diambil melalui suatu saluran pengeluaran. Fase uap dan cair yang meninggalkan tangki pemisah berada dalam kesetimbangan. Operasi kondensasi parsial adalah suatu pemisahan stage tunggal (single stage equibrilium).

\section{2) Distilasi Sederhana}

Distilasi sederhana atau biasa dikenal sebagai distilasi batch adalah proses yang digunakan untuk memisahkan campuran larutan binar ataupun multikomponen. Contoh operasi distrilasi sederhanan adalah peralatan distilasi di laboratorium. Larutan diisikan ke dalam labu distilasi, dipanaskan untuk menjaga cairan tetap mendidih dan uap yang terbentuk diambil secara kontinyu dan kemudian diembunkan.

\section{3) Destilasi Uap}

Pada kasus dimana ingin dipisahkan komponen volatil A yang terdapat pada suatu campuran organik biner terdiri dari komponen A dan komponen non-volatil B. Pemisahan dapat dilakukan menggunakan destilasi uap (steam). Komponen A dan B tidak saling melarut, demikian juga komponen A dan B tidak larut dalam air. Kasus-kasus seperti ini banyak ditemui, contohnya pada pengambilan hidrokarbon ringan dari minyak-minyak berat (yang non volatil), pengambilan komponen yang sensitif terhadap suhu (minyak atsiri, parfum, vitamin) dari campuran fase organik.

Titik didih campuran A dan B ditentukan oleh tekanan uap komponen A dan konsentrasinya, $x_{\mathrm{A}}$ dalam campuran. Hubungan dengan tekanan total dengan tekanan total adalah :

$$
P_{t}=P_{A}^{o} \cdot X_{A}+P_{B}^{o} \cdot\left(1-X_{A}\right)
$$

Pada distilasi uap, yang melibatkan komponen volatil A dalam campuran A dan komponen non-volatil B, tekanan total pada titik didih dihubungkan dengan tekanan parsial dari kedua fase cairan yang tak terlarut sebagai berikut :

$$
P_{t}=P_{W}^{o} \cdot+P_{A}^{o} \cdot X_{A}
$$

Tekanan uap $P_{W}^{o}$. dan $P_{A}^{o}$ ditentukan olah $\mathrm{T}$, yaitu suhu bubble point dari operasi distilasi uap. Untuk operasi pada tekanan konstan, dengan turunnya fraksi mol komponen A dalam fase organik selama operasi akan menyebabkan suhu distilasi akan naik. Suhu maksimum dari distilasi uap adalah suhu didih air pada tekanan sistem $P_{t}$. Oleh sebab itu, kisaran suhu operasi distilasi uap tergantung pada nilai $P_{t}, x_{A}$, tekanan uap $P_{W}^{o}$.dan $P_{A}^{o}$. 


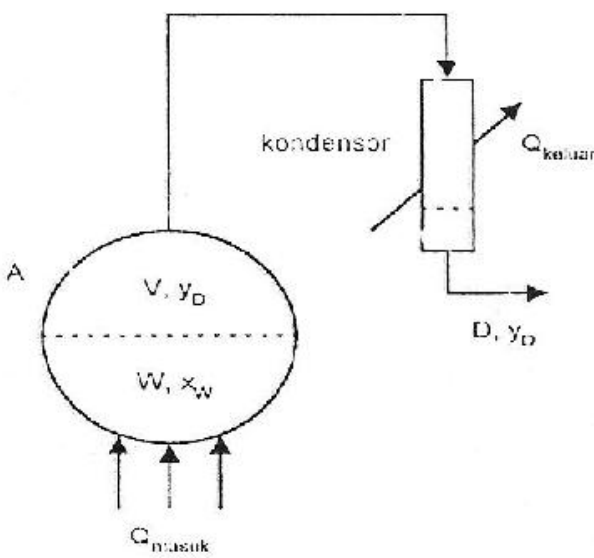

Gambar 1. Bentuk destilasi uap (steam destillation)

\section{B. Proses Destilasi Pada Minyak Bumi}

Proses destilasi dalam kilang minyak bumi merupakan proses pengolahan secara fisika yang primer yang mengawali semua proses-proses yang diperlukan untuk memproduksi BBM dan Non-BBM. Proses destilasi ini dapat menggunakan satu kolom atau lebih menara destilasi. Secara fundamental semua proses-proses destilasi dalam kilang minyak bumi adalah sama. Semua proses destilasi memerlukan beberapa peralatan yang penting yaitu:

- Pemanas uap menguapkan minyak bumi

- Kondensor dan cooler

- Menara fraksionas

- Kolom stripping

- Wadah penampung hasil destilasi

Proses pemisahan secara distilasi dengan mudah dapat dilakukan terhadap campuran, dimana antara komponen satu dengan komponen yang lain terdapat dalam campuran

- Dalam keadaan standar berupa cairan, saling melarutkan menjadi campuran homogen.

- Mempunyai sifat penguapan relatif $(\alpha)$ cukup besar.

- Tidak membentuk cairan azeotrop.

Pada proses pemisahan secara destilasi, fase uap akan segera terbentuk setelah sejumlah cairan dipanaskan. Uap dipertahankan kontak dengan sisa cairannya (dalam waktu relatif cukup) dengan harapan pada suhu dan tekanan tertentu, antara uap dan sisa cairan akan berada dalam keseimbangan, sebelum campuran dipisahkan menjadi distilat dan residu.

Uap yang terbentuk selanjutnya diembunkan dan dipanaskan secara berulangulang, maka akhirnya akan diperoleh komponen-komponen turunan dari minyak bumi dalam keadaan yang relatif murni. Gambar 2. memperlihatkan system destilasi minyak bumi yang menggunakan menara bertingkat sebagai kondensor.

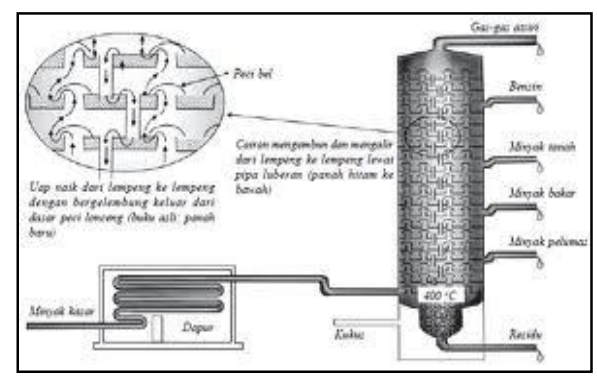

Gambar 2. Model proses estilasi minyak bumi dengan kondensor bertingkat

\section{Sampah Plastik Buangan Rumah Tangga/Industri}

\section{1). Definisi Plastik}

Plastik adalah senyawa polimer yang terbentuk dari polimerisasi molekul-molekul kecil (monomer) hidrokarbon yang membentuk rantai yang panjang dengan struktur yang kaku. Plastik juga disebut sebagai senyawa sintesis dari minyak bumi yang dibuat dengan reaksi polimerisasi molekul-molekul kecil (monomer) yang sama, sehingga membentuk rantai panjang dan kaku dan akan menjadi padat setelah temperatur pembentukannya. Plastik memiliki titik didih dan titik beku yang beragam, tergantung dari monomer pembentuknya. Monomer yang sering digunakan adalah etena (C2H4), propena (C3H6), styrene (C8H8), vinil klorida, nylon dan karbonat(CO3).

Penamaan dari plastik sesuai dengan nama monomer-nya dan diberi awalan poli-. Contohnya, plastik yang terbentuk dari monomer-monomer propena, namanya adalah polipropilena. Hampir semua plastik sulit untuk diuraikan. Plastik yang memiliki ikatan 
karbon rantai panjang dan memiliki tingkat kestabilan yang tinggi, sama sekali tidak dapat diuraikan oleh mikroorganisme sehingga tidak hancur di dalam tanah. Makanya plastik disebut sebagai sampah anorganik yang menyebabkan pencemaran (polusi) pada tanah. Plastik juga mencakup produk polimerisasi sintetik atau semisintetik. Mereka terbentuk dari kondensasi organik atau penambahan polimer dan bisa juga terdiri dari zat lain untuk meningkatkan performa atau ekonomi.

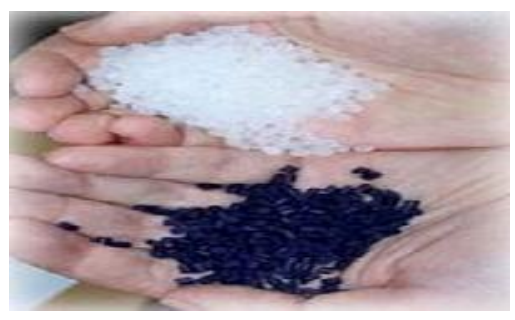

Gambar 3. Biji plastik yang siap untuk diproses lebih lanjut

Ada beberapa polimer alami yang termasuk plastik. Plastik didesain dengan variasi yang sangat banyak dalam properti yang dapat menoleransi panas, keras, "reliency" dan lain-lain. Akibat kemampuan adaptasinya, komposisi yang umum dan beratnya yang ringan memastikan plastik digunakan hampir di seluruh bidang industri.

\section{2)Jenis-Jenis Plastik}

Menurut Ahvenainen, Raija (2003) plastik dapat digolongkan berdasarkan:

\section{a. Sifat Fisikanya}

\section{> Termoplastik}

Merupakan jenis plastik yang bisa didaur-ulang lagi dengan proses pemanasan ulang. Contoh: Polietilen (PE), Polistiren (PS), Acrylonitrile butadiene styrene (ABS), Polikarbonat (PC). Plastik jenis Polietilen (PE) dibedakan lagi atas 7 tingkatan seperi pada gambar 4.

Bentuk-bentuk plastik jenis polietilen (PE) yang banyak dijumpai pemakaiannya di masyarakat dengan berbagai keperluan, seperti botol kemasan air mineral, jepitan rambut, casing $\mathrm{CD}$ dan sebagainya. Plastik jenis polietilen ini dibedakan pemakaiannya yang ditandai dengan angka 1 hingga 7.
Plastik jenis polietilen (PE) dibedakan lagi menjadi 7 tingkatan yang dibedakan atas jenis polimernya. Dilambangkan dengan segitiga panah yang diberi angka di dalamnya dari angka 1 hingga 7 . Lambang segitiga panas bertanda angka 1 disebut PET (Polyethylene Terephtalate); angka 2 disebut HDPE (High Density Polyethylene); tanda angka 3 disebut PVC (Polyvinyl Chloride); tanda angka 4 disebut LDPE (Low Density Polyethylene); tanda angka 5 disebut PP (Polypropylene), tanda angka 6 disebut PS (Polystyrene), tanda angka 7 disebut Multilayer. Umumnya ketujuh jenis plastik polietilen ini banyak sekali dijumpai penggunaannya di tengah-tengah masyarakat. Jika sudah rusak umumnya menjadi sampah dan sangat merusak lingkungan. Yang paling banyak dijumpah menjadi sampah adalah jenis PET (Polyethylene Terephtalate) karena banyak digunakan untuk botol air mineral dan botolbotol minuman ringan lainnya. Gambar 6 hingga gambar 8 adalah beberapa jenis plastik polietilen dan turunannya berdasarkan jenis polimer pembentuknya.

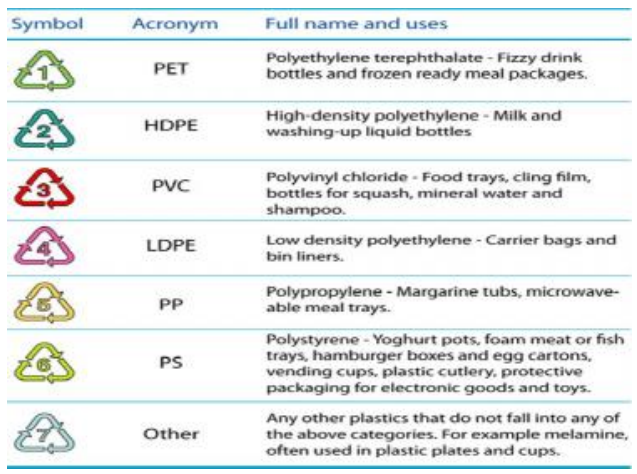

Gambar 4. Simbol dan tingkatan plastik jenis polietilen

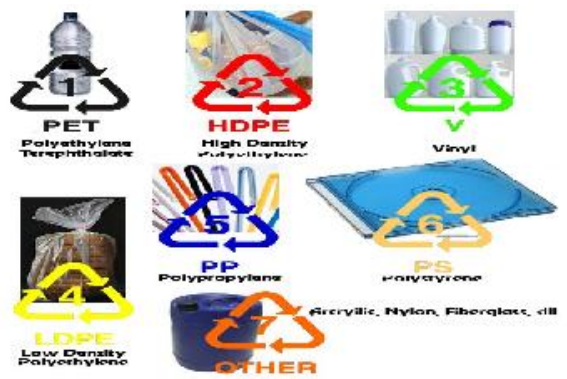


Gambar 5. Contoh bentuk plastik jenis polietilen

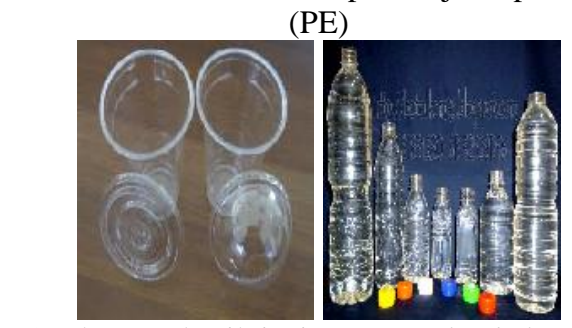

Gambar 6. Plastik jenis PET (Polyethylene Terephtalate)
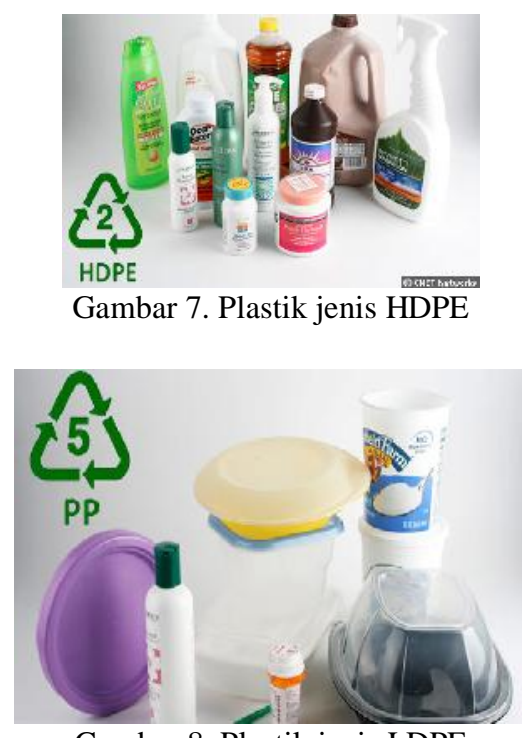

Gambar 8. Plastik jenis LDPE

(Low Density Polyethylene)

bening. Salah satu contohnya adalah plastik botol air mineral ukuran gelas dan ukuran botol serta botol minuman lainnya yang berwarna bening. Plastik jenis ini terasa lebih lunak dan lembut dibanding dengan plastik jenis lainnya.

Pemilihan jenis plastik PET (Polyethylene Terephtalate) pada penelitian tahun pertama ini karena plastik jenis ini sangat banyak dijumpai sebagai produk buangan masyarakat setelah mengadakan acara pesta, wisuda, rapat-rapat dan pertemuan lainnya. Mesin destilasi yang dirancang bangun memang tidak dibatasi pada satu jenis plastik saja, bisa juga digunakan untuk berbagai jenis plastik, akan tetapi dengan terbatasnya waktu dan biaya maka penelitian untuk tahap pertama ini pada plastik jenis plastik PET (Polyethylene Terephtalate.) Setiap kali pengujian digunakan plastik jenis Polyethylene Terephtalate sebanyak $2,5 \mathrm{~kg}$. Plastik dimasukan ke dalam ruang pembakaran, lalu kompor dihidupkan sedemikian rupa hingga temperatur dalam ruangan berkisar antara $300-400^{\circ} \mathrm{C}$. Uap hasil pembakaran ditampung pada kolom uap untuk selanjutnya dikondensasikan di dalam kondensor. Setiap pengujian dilakukan sekitar 150 menit.

\section{HASIL DAN PEMBAHASAN}

\section{Metode}

Penelitian ini merupakan penelitian eksperimen, dengan tujuan mengembangkan dan mengimplemen- tasikan serta menghasilkan mesin destilasi pengolah sampah plastik menjadi bahan bakar minyak menggunakan kondensor (condenser) bertingkat dan pendingin kompresi uap. Objek penelitian adalah sampah plastik dan mesin destilasi fraksinasi. Sampah plastik yang dijadikan sampel pengujian adalah sampah plastik jenis Polytehylene (PE) yang berbahan dasar polimer PET (Polyethylene Terephtalate).

Plastik jenis ini umunya dihasilkan oleh produk buangan (komoditi) rumah tangga yang berwarna

Pengujian pada penelitian Hibah Bersaing tahun pertama ini difokuskan kepada unjuk kerja (performance) mesin destilasi sampah plastik. Pengujian dibedakan atas pengujian kosong dan pengujian dengan menggunakan sampah plastik. Pengujian kosong dimaksudkan agar diketahui unjuk kerja mesin ini sebelum diberi beban pendinginan yaitu uap hasil pembakaran. Setelah pengujian kosong, maka selanjutnya dilakukan pengujian dengan menggunakan sampah plastik. Sampah plastik yang dijadikan sampel pengujian adalah sampah plastik jenis polyethylene terephtalate (PET) dan jenis high density polyethylene (HDPE). Setiap pengujian plastik yang dibakar adalah 
2,5 kg dalam waktu 150 menit. Data yang didapatkan dari hasil pengujian mesin destilasi sampah plastik ini, juga dibedakan atas dua bagian yaitu; pertama adalah gas hidrokarbon dan bahan bakar minyak yang dihasilkan, kedua adalah data laju penurunan temperatur yang terjadi dalam ruang pendingin.

\section{a Gas Hidrokarbon dan Bahan Bakar Minyak Yang Dihasilkan}

Gas hidrokarbon yang dihasilkan dari pembakaran sampah plastik ditampung dalam menara uap dan sebagian dari gas hidrokarbon ini terkondensasi menjadi bahan bakar minyak. Dari 2,5 kg sampah plastik yang dibakar pada setiap kali pengujian dalam waktu 150 menit pengujian yang banyak dihasilkan baru gas hidrokarbon dengan volume sekitar 20 liter. Dalam beberapa kali pengujian yang dilakukan baik menggunakan sampah plastik jenis polyethylene terephtalate (PET) maupun jenis plastik high density polyethylene (HDPE) peneliti belum mendapatkan hasil yang maksimal sesuai dengan rencana penelitian.

Dalam penelitian ini direncanakan setiap pembakaran plastik $2,5 \mathrm{~kg}$ jenis polyethylene terephtalate (PET) maupun jenis plastik high density polyethylene (HDPE) maka diharapkan didapatkan gas hidrokarbon sekitar 10 hingga 15 liter dan bahan bakar minyak hasil kondensasi sekurang-kurangya 300 hingga $400 \mathrm{ml}$. Namum kondisi tersebut belum tercapai hingga terakhir pengujian. Meskipun telah dilakukan banyak perubahanperubahan terhadap mesin destilasi terutama pada komponen kondensasinya, namun masih belum menghasilkan seperti apa yang diharapkan.

Hasil pengujian yang dapat disampaikan pada laporan penelitian ini hingga pengujian terkahir adalah; gas hidrokarbon dengan volume sekitar 20 liter dan bahan bakar minyak $15 \mathrm{ml}$. Gas hidrokarbon yang dihasilkan dari hasil pembakaran ditampung dengan menggunakan kantong plastik, jika penuh lalu diganti kantong plastiknya dengan yang baru. Gas hidrokarbon yang didapat tersebut tidak bisa disimpan dalam waktu yang lama di dalam plastik dan lama kelamaan akan menguap ke udara. Sebagian tim peneliti bakar untuk membuktikan bahwa yang dihasilkan tersebut betul-betul gas dan hasilnya gas yang ada dalam kantong plastik tersebut dapat menyala dengan baik seperti layaknya gas LPG. Bahan bakar minyak yang dihasilkan tim peneliti coba dokumentasi-kan cepat seperti pada gambar 9. Bahan bakar minyak yang dihasilkan diperoleh dari saluran kondensasi bensin dan minyak tanah. Bentuk fisik dan bau dari bahan bakar minyak yang dihasilkan dari kedua saluran ini hampir sama. Sama-sama bening dan berbau menyengat menyerupai aftur. Secara kimia tim belum menguji hasil bahan bakar minyak hasil kondensasi ini.

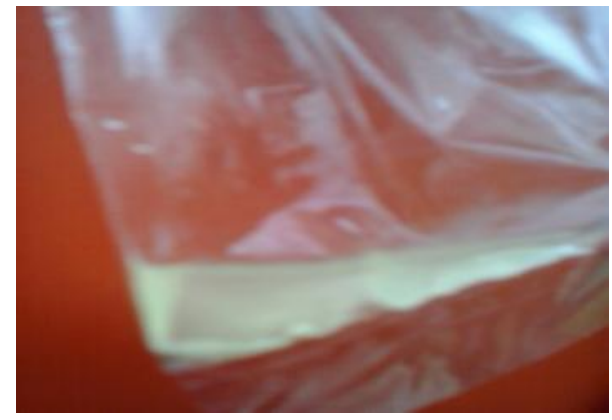

Gambar 9. Bahan bakar minyak hasil kondensasi pada saluran bensin

Dari gambar 9 terlihat bahwa secara fisik tidak tampak perbedaan yang signifikan bahan bakar minyak hasil kondensasi yang berasal dari saluran kondensasi bensin dengan saluran kondensasi minyak tanah. Hasil analisa tim peneliti dapat disimpulkan sementara, hal ini terjadi diakibatkan oleh tabung penampung uap yang disebut dnegan menara uap yang berfungsi sebagai fraksinasi uap tidak bekerja sebagaimana mestinya. Ukuran tinggi masih terlalu kurang dan diameternya terlalu besar. Secara teori menara uap ini harus lebih tinggi lagi yang yang ada sekarang lebih kurang 15 meter. Jika hal ini dapat diwujudkan maka proses fraksinasi uap sesuai dengan titik didihnya akan berlangsung dengan baik. Hasil kondensasi yang diharapkan menjadi minyak bensin, minyak tanah dan solar (diesel) akan diperoleh dengan baik. Dari gambar 9 juga dapat dianalisa bahwa proses kondensasi 
dalam ruang kondensor bertingkat belum berjalan sebagaimana mestinya. Hal ini terlihat dari hasil kondensasi yang belum maksimal baru sekitar $15 \mathrm{ml}$ dalam setiap kali pengujian, sisanya masih berbentuk gas hidrokarbon yang dapat dimanfaatkan. Perlu juga disampaikan pada laporan penelitian ini bahwa hasil destilasi lain yang tidak kami dokumentasikan disini adalah residu. Residu merupakan hasil sampingan dari proses destilasi sampah plastik, namun hasilnya masih sangat sedikit.

\section{b. Uji Kinerja Mesin Destilasi Sampah Plastik}

Seperti telah disebutkan di atas bahwa pengujian terhadap kinerja mesin destilasi sampah plastik dilakukan dengan beberapa variasi yaitu pengujian kosong dan pengujian berisi sampah plastik jenis polyethylene terephtalate (PET) dan jenis plastik high density polyethylene (HDPE). Contoh plastik jenis polyethylene terephtalate (PET) adalah botol bekas miniuman air mineral yang berwarna bening. Sedangkan contoh plastik jenis high density polyethylene (HDPE) adalah kantong plastik kresek. Sampah plastik ini dipotong kecil-kecil lalu dipanaskan dalam ruang pembakaran hingga temperatur didihnya lebih kurang $300^{\circ} \mathrm{C}$. Tiap variasi pengujian dia atas diperlukan waktu 150 menit.

\section{1) Laju Penurunan Temperatur Dalam Ruang Pendingin}

Laju penurunan temperatur dalam ruang pendingin dipengaruhi oleh banyak faktor; diantaranya adalah beban pendinginan dari uap yang akan dikondensasikan, lampu dan beban pendinginan dari panas lingkungan yang masuk ke dalam ruang pendingin.

\section{a) Pengujian Kosong Settingan Thermostate 4 dan 6}

Pada pengujian kosong pada settingan thermsotate 4 terlihat laju penurunan temperatur cukup signifikan pada awal-awal pengujian. Namun setelah mendekati temperatur $5^{\circ} \mathrm{C}$ terjadi perlambatan laju penurunan temperatur. Pada setingan thermostate 6 laju penuruan temperatur dalam ruang pendingin terlihat lebih cepat dari pada settingan thermsotate 4 terutama pada awalawal proses pengeringan. Hal ini dapat dimaklumi, karena settingan 6 menghasilkan suplai udara dingin dengan temperatur yang lebih rendah oleh mesin pendingin. Capaian temperatur terendah dalam ruang pengering yang dapat dicapai oleh mesin pendingin pada settingan thermostate 4 adalah $5^{\circ} \mathrm{C}$.

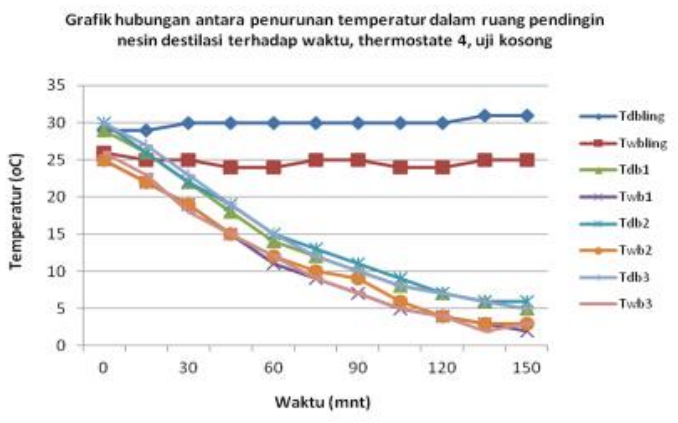

Gambar 10. Laju penurunan temperatur dalam ruang pendingin mesin destilasi pada settingan thermostate 4 dan pengujian kosong.

Capaian temperatur $5^{\circ} \mathrm{C}$ dalam ruangan pendingin pada settingan thermsotate 4 pada prinsipnya secara teori sudah cukup untuk mengkondensasikan uap hasil pembakaran sampah plastik. Pada gambar 11 terlihat laju penurunan temperatur dalam ruang pengering untuk settingan thermsotate 6 lebih cepat dibandingkan dengan settingan thermostate 4 terutama juga diwal-awal pengujian. Kemampuan mesin pendingin untuk mendinginkan udara suplai pada settingan thermsotate 6 sedikit lebih tinggi dari settingan 4. Hal ini terlihat dari data penelitian yang dihasilkan bahwa capaian temperatur terendah yang dapat dicapai juga berbeda yakni bisa mencapai $2^{\circ} \mathrm{C}$. Capaian temperatur $2^{\circ} \mathrm{C}$ tentu akan mempercepat proses kondensasi uap hasil pembakaran di dalam ruang pendingin. 


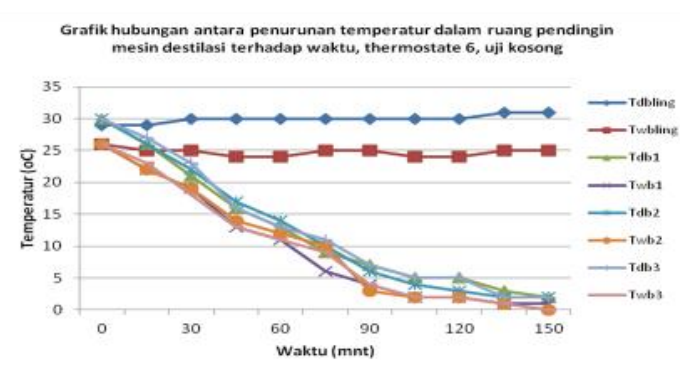

Gambar 11. Laju penurunan temperatur dalam ruang pendingin mesin destilasi pada settingan thermostate 6 dan pengujian kosong. b) Pengujian Menggunakan Sampah Plastik

Pada Ruang Pembakaran Settingan Thermostate 6

Pada pengujian menggunakan sampah plastik dalam ruang pembakaran, maka settingan thermostate mesin pendingin digunakan 6. Pada settingan ini capaian temperatur yang dihasilkan dalam ruang pendingin bisa mencapai $2^{\circ} \mathrm{C}$ hingga $0^{\circ} \mathrm{C}$. Secara teori kondisi ini akan mempercepat terjadinya proses kondensasi gas hasil pembakaran plastik dalam ruangan pendingin. Makanya untuk pengujian dengan menggunakan sampah plastik settingan thermostate yang digunakan adalah 6 .

Laju penurunan temperatur udara dalam ruang pendingin pada pengujian berisi sampah plastik jenis polyethylene terephtalate (PET) dan jenis high density polyethylene (HDPE) dapat terlihat pada gambar 12 dan 13.

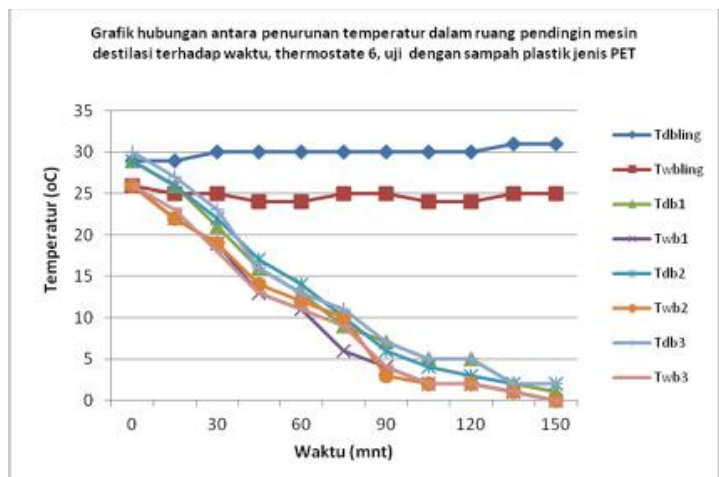

Gambar 12. Laju penurunan temperatur dalam ruang pendingin mesin destilasi pada settingan thermostate 6 dan pengujian dengan sampah plastik jenis PET

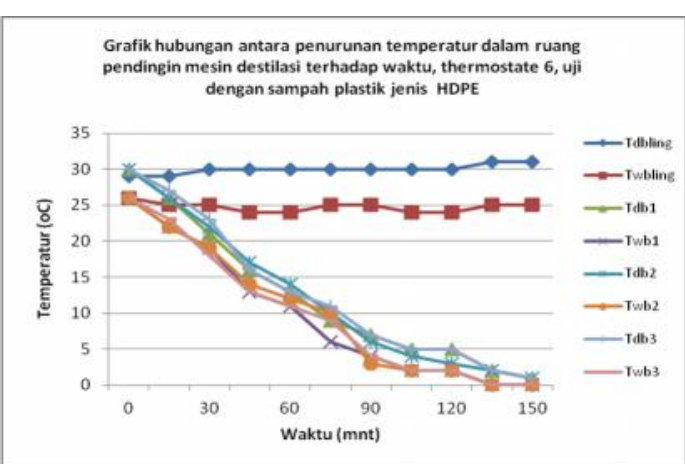

Gambar 13. Laju penurunan temperatur dalam ruang pendingin mesin destilasi pada settingan thermostate 6 dan pengujian dengan sampah plastik jenis HDPE

Hal yang sama juga terjadi pada proses pengujian pada hari terakhir. Pada pengujian ini, laju penurunan temperatur pada ruang pendingin terlihat hampir sama dengan pengujian terdahulu yang menggunakan sampah plastik. Capaian temperatur terendah dalam ruang pendingin sekitar $2^{\circ} \mathrm{C}-0^{\circ} \mathrm{C}$ seperti terlihat pada gambar 14 .

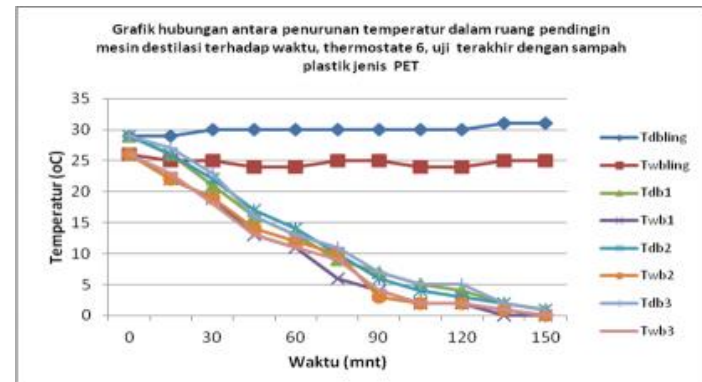

Gambar 14. Laju penurunan temperatur dalam ruang pendingin mesin destilasi pada settingan thermostate 6 dan pengujian terakhir dengan sampah plastik jenis PET

\section{2) Hubungan Kelembaban Udara Dalam Ruang Pendingin dengan Waktu Pengujian}

Kelembaban udara dalam ruang pendingin secara prinsip tidak berubah secara signifikan selama proses pengujian. Hal ini terjadi karena gas hasil pembakaran plastik tidak bersentuhan langsung dengan udara dingin di dalam ruang pendingin. Yang banyak berperan dalam proses kondensasi gas hasil pembakaran dalam ruang pendinginadalah proses perpindahan panas dari gas ke pipa galvanis dan dari pipa galvanis ke udara dingin dalam ruang. 
Perpindahan panas yang terjadi secara konveksi, konduksi dan konveksi lagi.

\section{a) Pengujian Kosong Settingan Thermostate} 4 dan 6

Pada pengujian kosong baik pada settingan thermostate 4 atau 6 tidak terlihat perubahan kelembaban udara dalam ruang pendingin secara signifikan. Pada pengujian kosong ini tidak ada penambahan temperatur dari uap hasil pembakaran sampah plastik. Panas yang menjadi beban mesin pendingin hanya berasal dari panas lingkungan yang masuk melalui dinding ruang pendingin dan panas yang berasal dari lampu serta pertukaran udara jika pintu intip dibuka tutup. Jadi tidak terjadi perubahan temperatur yang signifikan dalam ruang pendingin yang dapat mempengaruhi perubahan kelembaban dalam ruang pendingin.

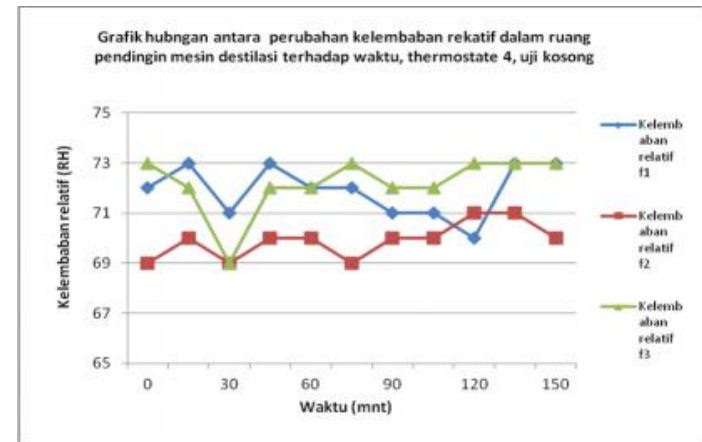

Gambar 15. Perubahan kelembaban relatif udara dalam ruang pendingin terhadap waktu pengujian, settingan thermostate 4, uji kosong.

Gambar 15 dan 16 adalah proses perubahan kelemban relatif udara dalam ruang pendingin selama proses pengujian kosong dengan settingan mesin thermostate mesin pendingin 4 dan 6 . Kelembaban udara dalam ruang pendingin pada pengujian kosong baik pada settingan thermostate 4 berkisar antara $69 \%$ hingga $73 \%$. Hal yang sama juga pada pengujian kosong settingan thermostate 6 , berkisar antara 68\% hingga $73 \%$.

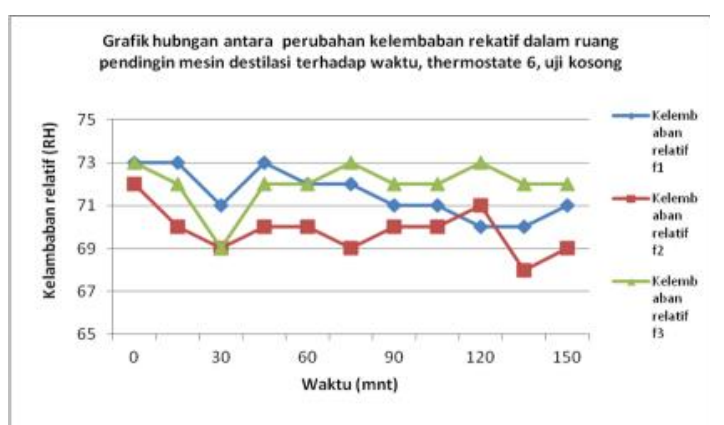

Gambar 16. Perubahan kelembaban relatif udara dalam ruang pendingin terhadap waktu pengujian, settingan thermostate 6 , uji kosong.

\section{b) Pengujian Menggunakan Sampah Plastik}

Pada Ruang Pembakaran Settingan Thermostate 6

Pengujian dengan menggunakan sampah plastik jenis polyethylene terephtalate (PET) dan jenis high density polyethylene (HDPE) dilakukan pada settingan thermostate 6 agar proses pendinginan berlangsung lebh cepat. Pada pengujian ini perubahan kelembaban relatif udara dalam ruang pendingin berkisar antara $68 \%$ hingga $73 \%$. Proses pengujian dengan menggunakan sampah plastik tidak membuat terjadinya perubahan kelembaban udara dalam ruang pendingin secara signifikan. Hal ini disebabkan beban pendinginan untuk pengkondensasian uap hasil pembakaran tidak terlalu besar.

Gambar 17 dan 18 adalah grafik yang menunjukan hubungan perubahan kelembaban relatif udara dalam ruangan dengan waktu. Pengujian dilakukan dengan menggunakan sampah plastik jenis PET dan HPDE dengan settingan thermostate 6 .

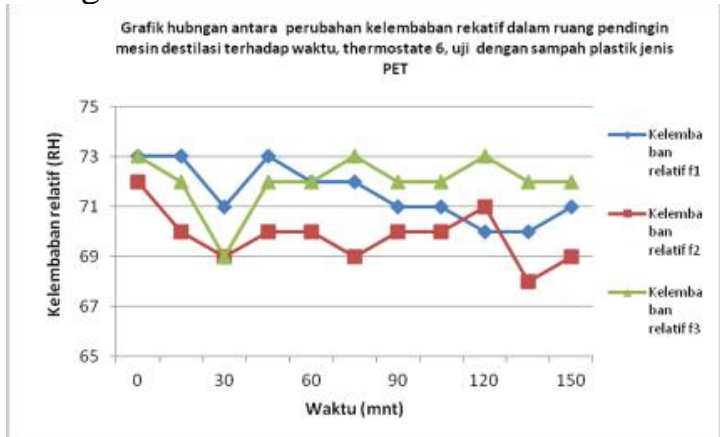

Gambar 17. Perubahan kelembaban relatif udara dalam ruang pendingin terhadap waktu pengujian, settingan thermostate 6, uji dengan sampah plastik jenis PET 


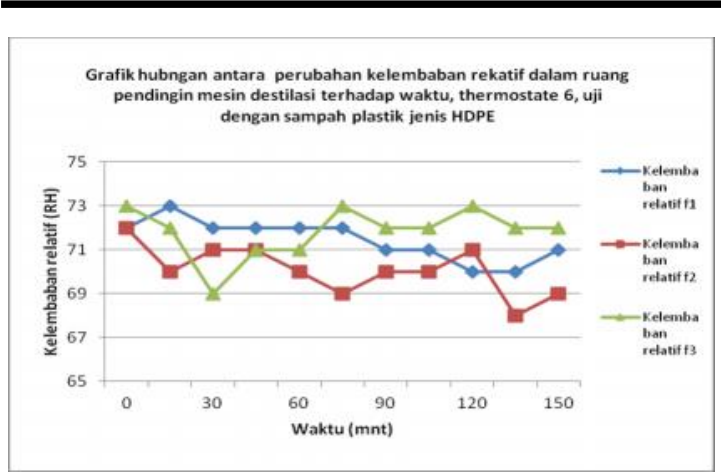

Gambar 18. Perubahan kelembaban relatif udara dalam ruang pendingin terhadap waktu pengujian, settingan thermostate 6, uji dengan sampah plastik jenis HDPE

Pada pengujian dihari terakhir dengan menggunakan sampah plastik jenis PET menghasilkan kondensat bahan bakar minyak sebanyak $15 \mathrm{ml}$, kelembaban relatif udara dalam ruang pendingin juga tidak mengalami perubahan yang cukup berarti. Perubahan kelembaban relatif udara yang terjadi hampir sama dengan pengujian menggunakan sampah plastik pada waktu sebelumnya. Kelembaban relatif udara dalam ruang pendingin berkisar antara $68 \%$ hingga $73 \%$ seperti ditunjukkan oleh gambar 19.

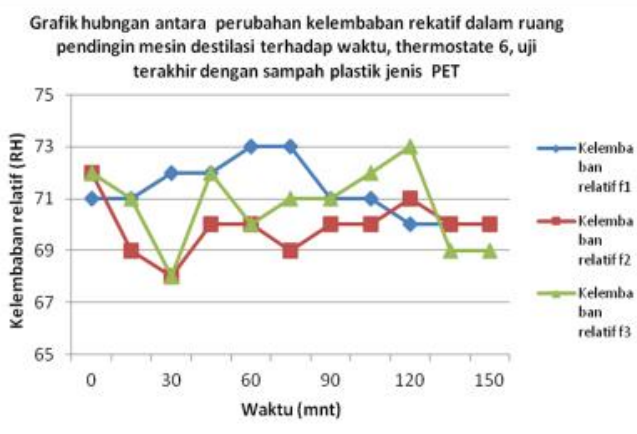

Gambar 19. Perubahan kelembaban relatif udara dalam ruang pendingin terhadap waktu pengujian, settingan thermostate 6, uji terakhir sampah plastik jenis PET

\section{3). Hubungan COP Mesin Pendingin dengan Waktu Pengujian}

Besarnya daya listrik yang disuplai ke kompresor mesin pendingin seharusnya sebanding dengan banyaknya energi dingin yang dapat termanfaatkan (Q,use) dalam mendinginkan produk dalam ruang pengering. Perbandingan antara energi dingin termanfaatkan (Q,use) dengan daya listrik yang disuplai ke dalam mesin pendingin disebut dengan unjuk kerja (coefficient of performance, COP) dari mesin pendingin. Pada penelitian ini juga diamati dan diukur daya listrik yang disuplai ke mesin pendingin, dan energi dingin yang bisa dihasilkan oleh mesin pendingin dan termanfaatkan oleh produk (Q,use). Hal ini dilakukan dengan tujuan agar diketahui pula kinerja dari mesin pendingin secara keseluruhan.

\section{a) Pengujian Kosong Settingan Thermostate 4 dan 6}

Pada gambar 20 dan 21 terlihat laju peningkatan kinerja atau Coefficient $O f$ Performance $(C O P)$ dari mesi pendingin. Kinerja mesin pendingin adalah kemampuan mesin pendingin dalam mendinginkan ruang pendingin dibagi dengan daya listrik yang disuplai oleh kompresor. Dalam mendinginkan ruang pendingin pada dasarnya yang manjadi dasar kemampuan pendinginan adalah beban panas yang dapat dibuang oleh mesin pendingin persatuan waktu.

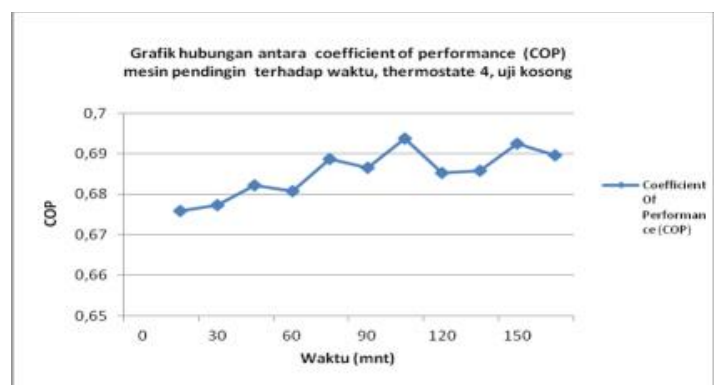

Gambar 20. Laju perubahan kinerja mesin pendingin terhadap waktu pengujian, settingan thermostate 4 , uji kosong.

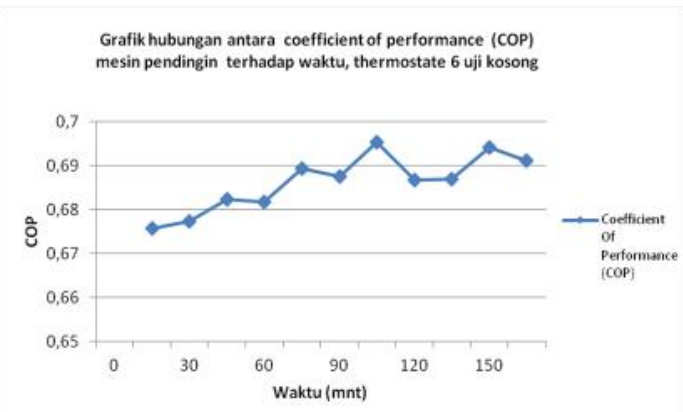

Gambar 21. Laju perubahan kinerja mesin pendingin terhadap waktu pengujian, settingan thermostate 6 , uji kosong

Dari gambar 19 dan 20 terlihat bahwa COP mesin cenderung meningkat seiring 
dengan waktu pengujian. Peningkatan COP mesin pendingin dalam kisaran $0,6,76$ hingga 0,693 .

\section{b) Pengujian Menggunakan Sampah Plastik} Pada Ruang Pembakaran Settingan Thermostate 6

Untuk pengujian dengan menggunakan sampah plastik, laju peningkatn COP mesin pendingin terlihat juga hampir sama dengan pengujian ksosong dengan kisaran antara 0,676 hingga 0,691. Hal sebetulnya menunjukan bahwa mesin pendingin dapat bekerja dengan baik. Mesin pendingin ini bekerja cukup stabil. Artinya diberi beban pendinginan atau tidak diberi beban pendinginan dalam bentuk uap panas hasil pembakaran dalam ruang pembakaran COP nya masih stabil. Hal ini dapat terlihat dari gambar 22 dan 23.

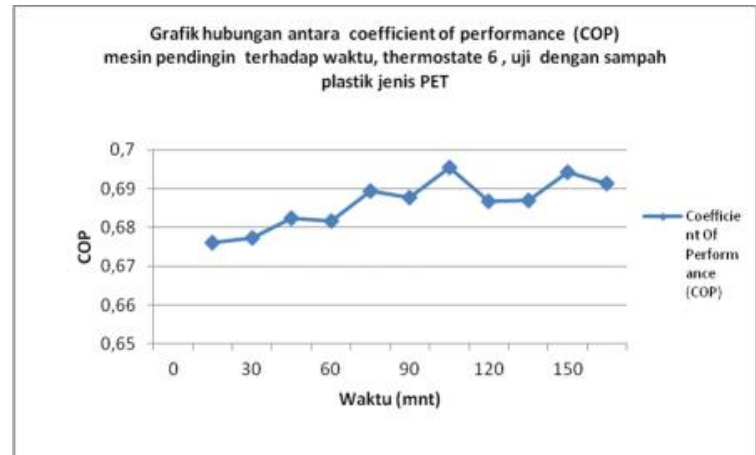

Gambar 22. Laju perubahan kinerja mesin pendingin terhadap waktu pengujian, settingan thermostate 6 , uji dengan sampah plastik jenis PET

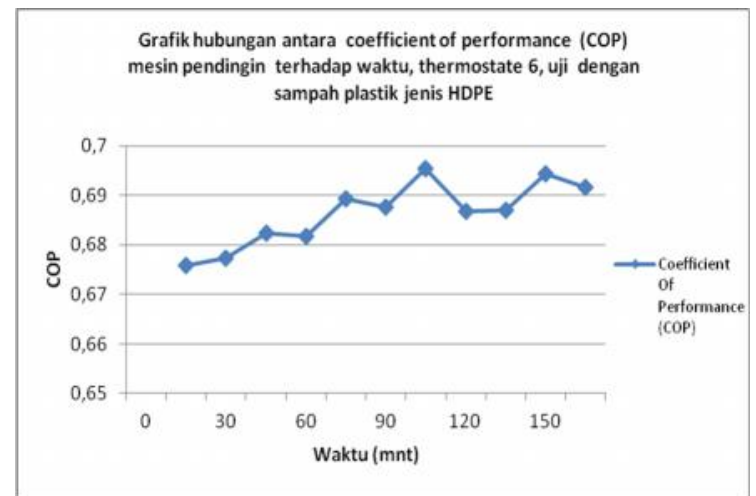

Gambar 23. Laju perubahan kinerja mesin pendingin terhadap waktu pengujian, settingan thermostate 6 , uji dengan sampah plastik jenis HDPE
Hal yang sama juga terlihat pada pengujian terakhir, perubahan COP mesin pedingin terlihat pada kisaran 0,676 hingga 0,692

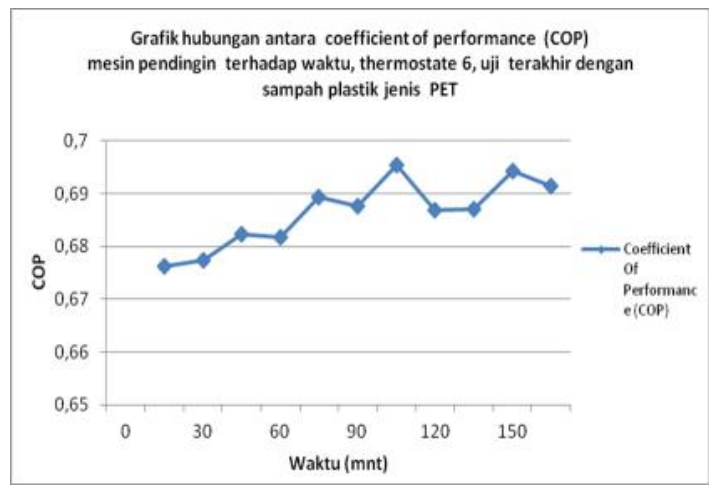

Gambar 5.17. Laju perubahan kinerja mesin pendingin terhadap waktu pengujian, settingan thermostate 6 , uji hari terakhir dengan sampah plastik jenis PET

Rendahnya nilai COP mesin pendingin yang diapatkan dari hasil pengujian ini menurut analisa tim penelitian dipengaruhi oleh banyak faktor diantaranya adalah kemampuan produk menyerap dingin yang disuplai oleh mesin pendingin mungkin rendah, banyaknya energi dingin yang terbuang ke luar ruangan akibat adanya kebocoran energi dari ruang pengering hasil rancang bangun.

\section{KESIMPULAN}

Dari hasil pengujian unjuk kerja, pengolahan dan analisis data yang telah dilakukan pada mesin destilasi pengolah sampah plastik menjadi bahan bakar minyak maka dapat diambil beberapa kesimpulan:

1. Secara teknis mesin destilasi pengolah sampah plastik menjadi bahan bakar minyak hasil rancang bangun pada penelitian ini dapat berfungsi, namun masih perlu dilakukan perbaikanperbaikan sebelum dilakukan untuk pengujian dalam skala yang lebih luas.

2. Ruang pendingin sudah berfungsi dengan baik, meskipun proses kondensasi tidak berhasil dicapai sebagaimana perencanaan semula. 
3. Mesin destilasi telah dapat menghasilkan kondensat berupa bahan bakar minyak (dicapai pada pengujian terakhir tanggal 16 Januari 2014) sebanyak lebih kurang $15 \mathrm{ml}$ dengan pembakaran sampah plastik $2,5 \mathrm{~kg}$. Bahan bakar yang dihasilkan belum teridentifikasi secara kimiawi.

4. Bahan bakar minyak yang dihasilkan terlihat cukup bersih dan secara fisik mendekati minyak aftur.

5. Menara uap tidak berfungsi sebagai tempat menfraksinasi uap hasil pembakaran, diameternya terlau besar dan ketinggiannya masih kurang.

6. Pengunaan sampah plastik jenis PET dan HDPE untuk di destilasi, berlangsung lebih cepat terurai menjadi uap. Dalam waktu kurang dari 2 jam uap telah terbentuk dalam ruang pembakaran. Hal ini ditandai dengan naiknya tekanan yang ditunjukan oleh pengukru tekanan (pressure gage).

\section{DAfTar Pustaka}

[1] Agung Suprihatin, S. Pd; Ir. Dwi Prihanto; Dr. Michel Gelbert. Pengelolaan Sampah. Malang: PPPGT / VEDC Malang. (1996).

[2] Ahvenainen, Raija. Modern Plastics Handbook (edisi ke-1st). Woodhead Publishing Limited.. hlm. 24.1. (2003).

[3] DKI Perlu Modernisasi Pengolahan Sampah (Republika edisi 18 Agustus 2004), Sampah Dapat Hasilkan Energi Listrik (www.energi.lipi.go.id edisi 6 Desember 2004. (2004).

[4] Aziza. plastik. www.wikipedia.org. diaskes pada tanggal 23 April 2013.

[5] Bachriansyah, S. Identifikasi plastik. Makalah Pelatihan Teknologi Pengemasan Industri Makanan dan Minuman, Departemen Perindustrian dan Perdagangan, Bogor. (1997).

[6] Biyanto, TR., Wahyudi, H., dan Santosa, HH, Control Strategy of Single Distillation Column Binary System of Methanol-Water. Journal Instrumentasi, Instrumentation Society of Indonesia, Jakarta. (2004).
[7] Biyanto, TR, Suhartanto,T, Widjiantoro, BL, Predicting Liquid-Vapor (LV) Composition at Distillation coloumn, Journal Of Science And Technology SONGKLANAKARIN - Thailand. (2008).

[8] Breeze,Paul et al. Renewable Energy Focus Handbook. Academic Press. Elsevier. Linacre House, Jordan Hill, Oxford OX2 8DP,UK. (2009).

[9] Bierley, A.W., R.J. Heat and M.J. Scott. Plastic Materials Properties and Aplications. Chapman and Hall Publishing: New York.

[10] Chem Edu 09. 29 April 2012. Pemanfaatan Limbah Plastik Menjadi Bahan Bakar Minyak. www.chemedu09.wordpress.com.

Diakses pada tanggal 28 Agustus 2012. (1988).

[11] Cleanup. Plastic. www.cleanup.com.au. Diakes pada tanggal 28 Agustus 2012.

[12] Diana Rahmawati, Pemodelan Kolom Distilasi Methanol-Air Menggunakan Jaringan Saraf Tiruan, Tesis Jurusan Teknik Elektro FTI-ITS Surabaya. (2004).

[13] Harper, Charles A. Plastics Materials and Processes: A Concise Incyclopedia". John Wiley \& Sons, Inc. ISBN 0-471-45603-9. (2003).

\section{Biodata Penulis}

Arwizet, Saat ini aktif sebagai Dosen di Jurusan Teknik Mesin Fakultas Teknik Universitas Negeri Padang. 